\title{
The anti-leukemic effect of a novel histone deacetylase inhibitor MCT-1 and 5-aza-cytidine involves augmentation of Nur77 and inhibition of MMP-9 expression
}

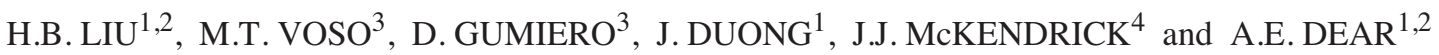 \\ ${ }^{1}$ Australian Centre for Blood Diseases, ${ }^{2}$ Biotechnology Division, Eastern Clinical Research Unit, Monash University, \\ 6th Floor Burnett Tower, 89 Commercial Road, Prahran 3181, Melbourne, Victoria, Australia; ${ }^{3}$ Institute of Hematology, \\ Catholic University, Rome, Italy; ${ }^{4}$ Department of Oncology, Box Hill Hospital, Box Hill 3128, Melbourne, Victoria, Australia
}

Received September 5, 2008; Accepted November 10, 2008

DOI: 10.3892/ijo_00000183

\begin{abstract}
A combination of demethylating agents and histone deacetylase inhibitors (HDACi) has been proposed as a novel therapy in leukemia and myelodysplasia. In HL-60 cells azacytidine (AZA) and Metacept-1 (MCT-1), a novel HDACi augmented inhibition of cell growth and increased apoptosis. In identifying a molecular mechanism responsible for these effects MCT-1 alone and in combination with AZA induced p15 ${ }^{\mathrm{INK} 4 \mathrm{~b}}, \mathrm{p} 21^{\mathrm{WAF} 1 / \mathrm{CIP} 1}$ and Caspase-3 whilst attenuating Bcl$\mathrm{XL}$ expression. Interestingly, MCT-1 in combination with AZA significantly induced the recently identified suppressor of leukemogenesis Nur77 and attenuated AZA-induced MMP-9 expression. The combination of MCT-1 and AZA is more effective in inhibiting leukemic cell growth and induction of apoptosis. Regulation of a recently identified tumour suppressor gene together with cell cycle, apoptosis and matrix degrading proteases may underpin the molecular mechanism responsible for these effects.
\end{abstract}

\section{Introduction}

Leukemogenesis results from a complex interplay between genetic abnormalities and epigenetic changes resulting in aberrant expression of genes critical to cell proliferation and survival. Epigenetic DNA methylation of promoter $\mathrm{CpG}$ islands is associated with gene silencing and utilizes DNA methyl transferease (DNMT) and recruitment of histone deacetylase (HDAC) to achieve this outcome (1).

Aberrant DNA methylation is frequently observed in acute leukemias and the myelodysplastic syndrome (MDS) (2-4) and

Correspondence to: Dr Anthony Dear, Australian Centre for Blood Diseases, Biotechnology Division, Eastern Clinical Research Unit, Monash University, 6th Floor Burnett Tower, 89 Commercial Road, Prahran 3181, Melbourne, Victoria, Australia

E-mail: anthony.dear@med.monash.edu.au

Key words: histone deacetylase inhibitor, 5-aza-cytidine, MMP-9 expression may result from hypermethylation-mediated repression of tumour suppressor genes including $\mathrm{p} 15^{\operatorname{INK} 4 \mathrm{~b}}(4,5)$.

The demethylating agent's 5-aza-cytidine and its deoxy derivative, decitabine are nucleoside analogues that inhibit DNA methylation by the trapping of DNA methyltransferases (DNMTs) and have recently been used in the treatment of MDS (6). AZA not only effectively switches off hypermethylation-mediated gene repression as seen for p15 $5^{\text {INK4b }}(4,5,7)$, but also induces apoptosis, via activation of the effector Caspase-3 in HL-60 cells (7) and may also be involved in the induction of the cell cycle inhibitor $\mathrm{p} 21^{\mathrm{WAF} 1 / \mathrm{CIP} 1}$, arresting acute myeloid leukemia cell lines in G1 of the cell cycle (8). Inhibition of Bcl-2 as well as Bcl-XL expression may also be involved in the AZA-induced apoptosis (9).

Of potential concern regarding clinical use of DNA methylation inhibitors are the results from in vitro observations identifying stimulation of cellular growth and invasion of solid tumours through reactivation of genes including MMP-9, silenced by promoter methylation (10-12).

Chromatin structure as determined by histone acetylation under the control of histone acetylase transferases (HAT's) and histone deacetylases (HDACs) synergizes with demethylation in the control of gene expression (13).

Histone deacetylase inhibitors (HDACi) represent a novel, structurally heterogeneous class of compounds that have recently been described to have significant therapeutic activity in the treatment of haematological malignancies (14). In vitro HDACi have been shown to up-regulate $\mathrm{p} 15^{\mathrm{INK} 4 \mathrm{~b}}, \mathrm{p} 21^{\mathrm{WAF} / \mathrm{CIP} 1}$ and Caspase-3 expression whilst down-regulating Bcl-XL and MMPs in cell lines $(8,15-21)$. Interestingly, HDACi have also been demonstrated to increase expression of the inducible orphan nuclear receptor Nur77 (22) whose expression has recently been demonstrated to be abrogated in acute myeloid leukemia (23).

Numerous in vitro studies together with recent preclinical and early phase clinical studies identify significant anti-leukemic activity of a combination of HDACi with demethylating agents with greater inhibition of growth and DNA synthesis and a greater loss of clonogenicity than that observed by single agent treatment in in vitro studies $(6,8,13,24-27)$. 
Previous studies have shown that Metacept-1 (MCT-1) a methyl sulfonamide analogue of the known hydroxamate HDACi Oxamflatin $(28,29)$ is also a potent inhibitor of histone deacetylase at concentrations in the micromolar range (30). Based on the known hypomethylating activity and clinical anti-leukemia activity of AZA and the recently reported HDACi activity of MCT-1 (30), we studied the effect of the combination of these agents in the HL-60 leukemia cell line and explored the molecular mechanisms responsible for these effects.

\section{Materials and methods}

Cell culture. HL-60 cells were cultured in RPMI-1640 (Gibco BRL) containing 10\% heat inactivated fetal calf serum and kept in a $5 \% \mathrm{CO}_{2}$ incubator at $37^{\circ} \mathrm{C}$. Agents [AZA (kind gift of Pharmion Australia) and Metacept-1 (MCT-1), synthesized in the Department of Chemistry, Monash University, Melbourne, Australia; MCT-1 was generated by methyl substitution of the phenyl group of Oxamflatin] were added to plates together with fresh medium every $24 \mathrm{~h}$ for stipulated times. AZA was dissolved in $\mathrm{H}_{2} \mathrm{O}$ with $0.2 \%$ acetic acid and used at a final concentration of $1.0 \mu \mathrm{M}$. MCT- 1 was dissolved in PBS with $1 \%$ DMSO and used at a final concentration of $0.5 \mu \mathrm{M}$. In combination experiments AZA and MCT-1 were added simultaneously to the cell culture medium. For cell growth and apoptosis assays control treatment (Con) consisted of $0.2 \%$ acetic acid together with $1 \%$ DMSO.

Growth inhibition assay. HL-60 cells in log phase were plated at a density of $0.2 \times 10^{6}$ in $10 \mathrm{ml}$ of medium. Cells were harvested at 24 and $96 \mathrm{~h}$. Cell viability was assessed using $0.4 \%$ trypan blue staining immediately after culture. Black staining cells were considered as non-viable cells and unstained bright cells as viable. All experiments were repeated a minimum of 4 times with averages displayed graphically.

Apoptosis assay. Apoptosis was determined by a photometric enzyme-immunoassay (ELISA), using a commercially available kit (Boehringer Mannheim). The assay was based on a quantitative sandwich enzyme-immunoassay principle using mouse monoclonal antibodies directed against DNA and histones, respectively. The mean of 3 or more experiments identifying apoptotic cell numbers is presented.

Histone isolation and Western blotting. Histones were isolated by acid extraction, as previously described (8). Cells $\left(5 \times 10^{6}\right)$ treated with or without drug were harvested and washed with phosphate-buffered saline (PBS). HL-60 cells were lysed in ice-cold lysis buffer [10 mM HEPES (pH 7.9), $1.5 \mathrm{mM} \mathrm{MgCl}_{2}$, $10 \mathrm{mM} \mathrm{KCl}, 0.5 \mathrm{mM}$ DTT and $1.5 \mathrm{mM}$ phenylmethylsulfonyl fluoride] and $5 \mathrm{M} \mathrm{H}_{2} \mathrm{SO}_{4}$ was added. After incubation on ice for $1 \mathrm{~h}$, the suspension was centrifuged and the supernatant was harvested, mixed with acetone at a ratio of 9:1 and incubated at $-20^{\circ} \mathrm{C}$ overnight. After centrifugation, the pellet was washed with $70 \%$ ethanol and air dried and the acidsoluble histone fraction was dissolved in $\mathrm{H}_{2} \mathrm{O}$. A BCA protein assay was then used for quantitation (Pierce) and histones were electrophoresed through a $15 \%$ SDS-PAGE gel and transferred to PVDF membrane. Membranes were incubated with anti-
Table I. Primers for RT-PCR and real-time PCR.

\begin{tabular}{l} 
Sequence \\
Primer \\
\hline p15' ${ }^{\text {INK4b }}$ \\
Forward 5'-CTGCGCGTCTGGGGGCTGC-3' \\
Reverse 5'-CCTCCCGAAACGGTTGACTCC-3' \\
p21 ${ }^{\text {wAFI/CIPl }}$ \\
Forward 5'-ATTAGCAGCGGAACAAGGAGTCAGCAT-3' \\
Reverse 5'-CTGTGAAAGACACAGAACAGTACAGGGT-3' \\
Caspase-3 \\
Forward 5'-GCAGCAAACCTCAGGGAAAC-3' \\
Reverse 5'-TGTCGGCATACTGTTTCAGCA-3' \\
Bcl-XL \\
Forward 5'-TTGGACAATGGACTGGTTGA-3' \\
Reverse 5'-GTAGAGTGGATGGTCAGTG-3 \\
MMP-9 \\
Forward 5'-GTACCGCTATGGTTACAC-3' \\
Reverse 5'-GCGACACCAAACTGGATGA-3' \\
GAPDH \\
Forward 5'-CCTGCACCACCAACTGCTTAGC-3' \\
Reverse 5'-CCAGTGAGCTTCCCGTCTAGC-3' \\
B-actin \\
Forward 5'-GACAGGATGCAGAAGGAGATTACT-3' \\
Reverse 5'-TGATCCACATCTGCTGGAAGGT-3' \\
Nur77 \\
Forward 5'-GCTGCAGAATGACTCCACC-3' \\
Reverse 5'-ACAGCAGCACTGGGCTTA-3' \\
\hline
\end{tabular}

acetylated histone H3 (Upstate Biotechnology), followed by horseradish peroxidase-conjugated secondary antibody. Immunoreactive bands were visualized by enhanced chemiluminescence. Experiments were performed independently a minimum of 3 times.

Semi-quantitative RT-PCR and real-time QPCR. RT-PCR was performed on total RNA extracted from HL-60 cells. For PCR primer sequences see Table I. All PCR products were sequenced to confirm the identities and repeated 3 times.

Scanning densitometry analyses were performed on RTPCR products using the GeneSnap imaging software (Synoptics, UK). Band intensity values for $\mathrm{p} 15^{\mathrm{INK} 4 \mathrm{~b}}$, p21 ${ }^{\text {WAF1/CIP1 }}$ Bcl-XL, Caspase-3 and MMP-9 mRNA were normalized to those for GAPDH mRNA and the resultant p15 ${ }^{\mathrm{INK} 4 \mathrm{~b}}, \mathrm{p} 21^{\mathrm{WAF} / \mathrm{CIP} 1}, \mathrm{Bcl}-\mathrm{XL}$, Caspase-3 and MMP-9: GAPDH ratios were plotted to illustrate variations in gene expression.

For QPCR, RNA was heated at $65^{\circ} \mathrm{C}$ for $10 \mathrm{~min}$ immediately prior to first-strand cDNA being generated using reverse transcriptase (Invitrogen, USA) with oligo (DT) ${ }_{15}$ primers, in the presence of $1 \mathrm{mM}$ of each dNTP and DTT. For real-time QPCR step, reaction volumes of $20 \mu 1$ contained SYBR-Green 1 buffer (Eppendorff, USA) and forward and reverse primers for $\beta$-actin or Nur77 (see Table I). Samples were run in duplicate with RNA preparations from 3 independent experiments. Real-time QPCR was run by 50 cycles $\left(95^{\circ} \mathrm{C} 15 \mathrm{sec}, 56^{\circ} \mathrm{C} 56 \mathrm{sec}, 68^{\circ} \mathrm{C} 45 \mathrm{sec}\right)$ and each PCR run also included triplicate wells of no template control 

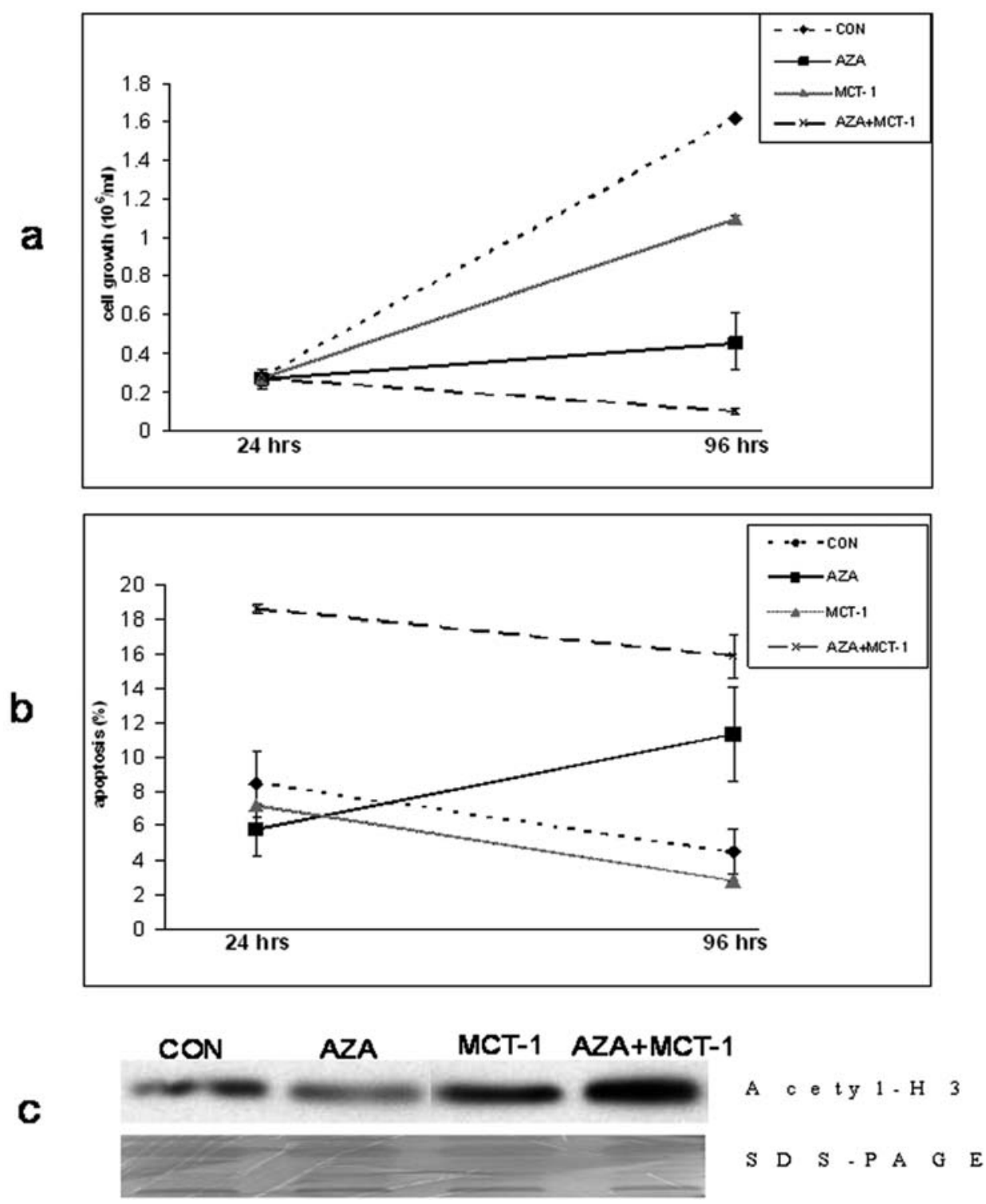

Figure 1. (a) Effects of AZA and MCT-1 on HL-60 cell viability. HL-60 cells were treated with $1 \mu \mathrm{M}$ of AZA, $0.5 \mu \mathrm{M}$ MCT-1 or both for 24 and 96 h. Numbers on the Y-axis represent the total number of viable cells at 24 and 96 h. (b) Percentage of apoptotic HL-60 cells quantitated at 24 and 96 h of treatment. (c) Western blotting of acetylated histone $\mathrm{H} 3$ protein expression in HL-60 cells treated with $1 \mu \mathrm{M}$ of AZA, $0.5 \mu \mathrm{M}$ MCT-1 or both for $24 \mathrm{~h}$ ( $\mathrm{n}=3$ ). Coomassie blue SDS-PAGE gel demonstrates protein loading.

(NTC). A melting point dissociation curve generated by the instrument was used to confirm that only a single product was present. The fluorescence resulted from the incorporation of SYBR-Green 1 dye into the double-stranded DNA produced during the PCR reaction and emission data were quantitated using the threshold cycle $\left(\mathrm{C}_{\mathrm{T}}\right)$ value. Data were normalized to $\beta$-actin and presented as the mean fold change compared with control.

SDS-PAGE and zymography studies. An aliquot of conditioned medium from HL-60 cells treated with AZA or/and MCT-1, together with untreated control cells, was electrophoresed through a $10 \%$ acrylamide SDS-PAGE gel containing $0.15 \%$ gelatin under non-denaturing conditions. Gels were washed twice with Triton X-100 and incubated in developing buffer at $37^{\circ} \mathrm{C}$ overnight. The gels were stained with Coomassie blue R250 and destained with water. A SDS-PAGE gel (without gelatin) was used as a loading control. All experiments were repeated 3 times.

Statistical methods. The effects of AZA and MCT-1 alone and in combination on cell growth, apoptosis and p15 $5^{\mathrm{INK} 4 \mathrm{~b}}$, p21 ${ }^{\text {WAF1/CIP1 }}$, Bcl-XL, Caspase-3, MMP-9 and Nur77 mRNA expression was assessed by analysis of variance (ANOVA). Specific differences were tested with Bonferroni's post hoc comparison test. Data are expressed as mean \pm SEM and $\mathrm{P}<0.05$ was considered statistically significant.

\section{Results}

AZA and MCT-1, alone and in combination, inhibits HL-60 cell growth. Cells were exposed to AZA $(1.0 \mu \mathrm{M})$ and/or MCT-1 $(0.5 \mu \mathrm{M})$ for up to $96 \mathrm{~h}$. Doses were based on previous in vitro studies identifying these concentrations as able to 
induce growth inhibition $(8,13,24,25,30)$. MCT-1 and AZA decreased the number of viable cells by $30-70 \%$ of control respectively at $96 \mathrm{~h}$ (Fig. 1a). As a control, HL-60 cells were grown in the presence of a combination of acetic acid and DMSO at the same concentration used in the presence of AZA and MCT-1 (Fig. 1a). The combination of both agents resulted in complete inhibition of cell growth at $96 \mathrm{~h}$ (Fig. 1a) suggesting that augmentation of inhibition of cell growth is achieved with a combination of AZA and MCT-1 over agents used singly.

AZA and MCT-1 in combination augments apoptosis in HL-60 cells. AZA treatment increased the number of apoptotic cells by 3-fold over control whilst MCT-1 had no significant effect on percentage of apoptotic cells at $96 \mathrm{~h}$ (Fig. 1b). The combination of both agents resulted in a 4-fold increase in the number of apoptotic cells over control suggesting that AZA-mediated apoptosis is augmented with a combination of AZA and MCT-1.

MCT-1 alone and in combination with AZA increase histone H3 acetylation in HL-60 cells. MCT-1 treatment significantly (1.5-fold) increased histone $\mathrm{H} 3$ acetylation after $24 \mathrm{~h}$ whilst no effect of AZA was observed (Fig. 1c). Interestingly, addition of AZA to MCT-1 resulted in a significant increase in induction of histone $\mathrm{H} 3$ acetylation after $24 \mathrm{~h}$, in the order of 2-3-fold, compared to MCT-1 treatment alone (Fig. 1c).

Effect of AZA and MCT-1 on regulation of cell cycle gene expression in HL-60 cells. Treatment of HL-60 cells with $0.5 \mu \mathrm{M}$ MCT- 1 or $1.0 \mu \mathrm{M}$ AZA alone for $24 \mathrm{~h}$ demonstrated an increase in expression of p15 ${ }^{\mathrm{INK} 4 \mathrm{~b}}$ (Fig. 2a). A combination of MCT-1 and AZA resulted in an additive and significant increase in $\mathrm{p} 15^{\mathrm{INK} 4 \mathrm{~b}}$ mRNA expression over single agent treatment (Fig. 2a). A minor increase in expression of another cell cycle regulatory protein $\mathrm{p} 21^{\mathrm{WAF} 1 / \mathrm{CIP} 1}$ was observed with single agent treatment although when used in combination MCT-1 and AZA treatment resulted in a significant induction of $\mathrm{p} 21^{\mathrm{WAF} 1 / \mathrm{CIP} 1}$ mRNA expression (Fig. 2b).

Effect of AZA and MCT-1 on apoptosis and tumour suppressor gene expression in HL-60 cells. AZA treatment resulted in a non-significant increase in Caspase- 3 mRNA expression, whilst MCT-1 treatment resulted in a significant increase in Caspase-3 expression (Fig. 3a). The combination of AZA and MCT-1 again resulted in a significant increase in induction of Caspase-3 expression over single agent treatment (Fig. 3a).

Single agent treatment resulted in a modest non-significant decrease in expression of Bcl-XL mRNA whilst combination treatment resulted in a significant inhibition of Bcl-XL mRNA expression (Fig. 3b).

Real-time PCR analysis demonstrated only a minor nonsignificant induction of Nur77 mRNA expression by single agent treatment, however the combination of MCT-1 and AZA resulted in a significant increase in Nur77 expression over single agent treatment (Fig. 3c).

Effect of AZA and MCT-1 on MMP-9 mRNA and proteolytic activity in HL-60 cells. In our in vitro cell system AZA treatment resulted in a significant increase in MMP-9 mRNA

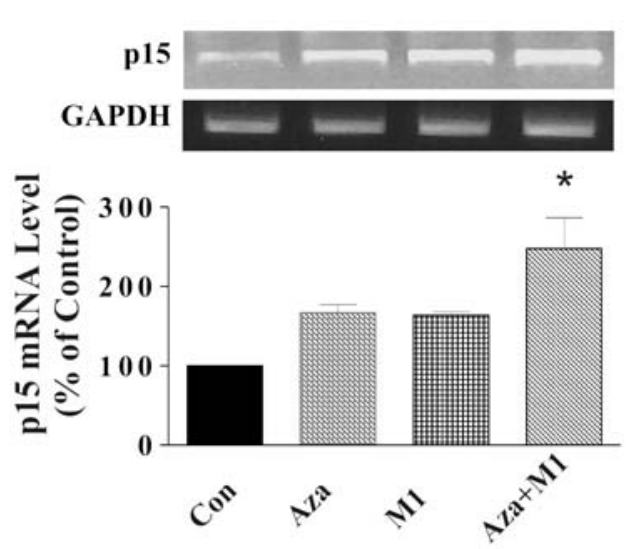

a

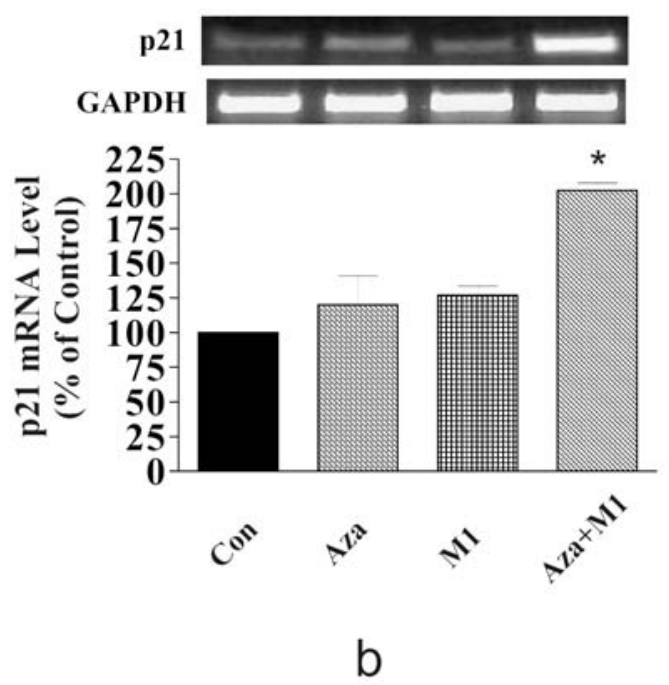

Figure 2. Effect of AZA and MCT-1 on p15 $5^{\mathrm{INK} 4 \mathrm{~b}}$ and $\mathrm{p} 21^{\mathrm{WAF} / \mathrm{CPP} 1} \mathrm{mRNA}$ expression in HL-60 cells. Con, HL-60 cells without treatment; AZA, cells treated with $1.0 \mu \mathrm{M}$ AZA; M1, cells treated with $0.5 \mu \mathrm{M}$ MCT-1; AZA+M1, cells treated with $0.5 \mu \mathrm{M}$ MCT-1 $+1.0 \mu \mathrm{M}$ AZA for $24 \mathrm{~h}$. ${ }^{*} \mathrm{P}<0.001$ $\mathrm{AZA}+\mathrm{M} 1$ vs. con and $\mathrm{n}=3$.

expression and proteolytic activity (Fig. 4a and b). Whilst MCT-1 alone had no effect on MMP-9 expression or activity the combination of AZA and MCT-1 completely and significantly abrogated the induction of MMP-9 identified with AZA alone (Fig. 4a and b).

\section{Discussion}

Preclinical and clinical studies suggest that both AZA and HDACi alone and in combination possess considerable therapeutic activity against a number of haematological malignancies $(6-8,14,24-27)$. Indeed, based on mechanism of action studies a combination of these two agents may prove more clinically efficacious than single agent treatment $(6,13,26,27)$.

Results of growth inhibition and induction of apoptosis studies, in keeping with previous in vitro studies utilizing a combination of AZA and known HDACi $(8,24,25)$, indicate that the combination of AZA and a novel HDACi MCT-1 

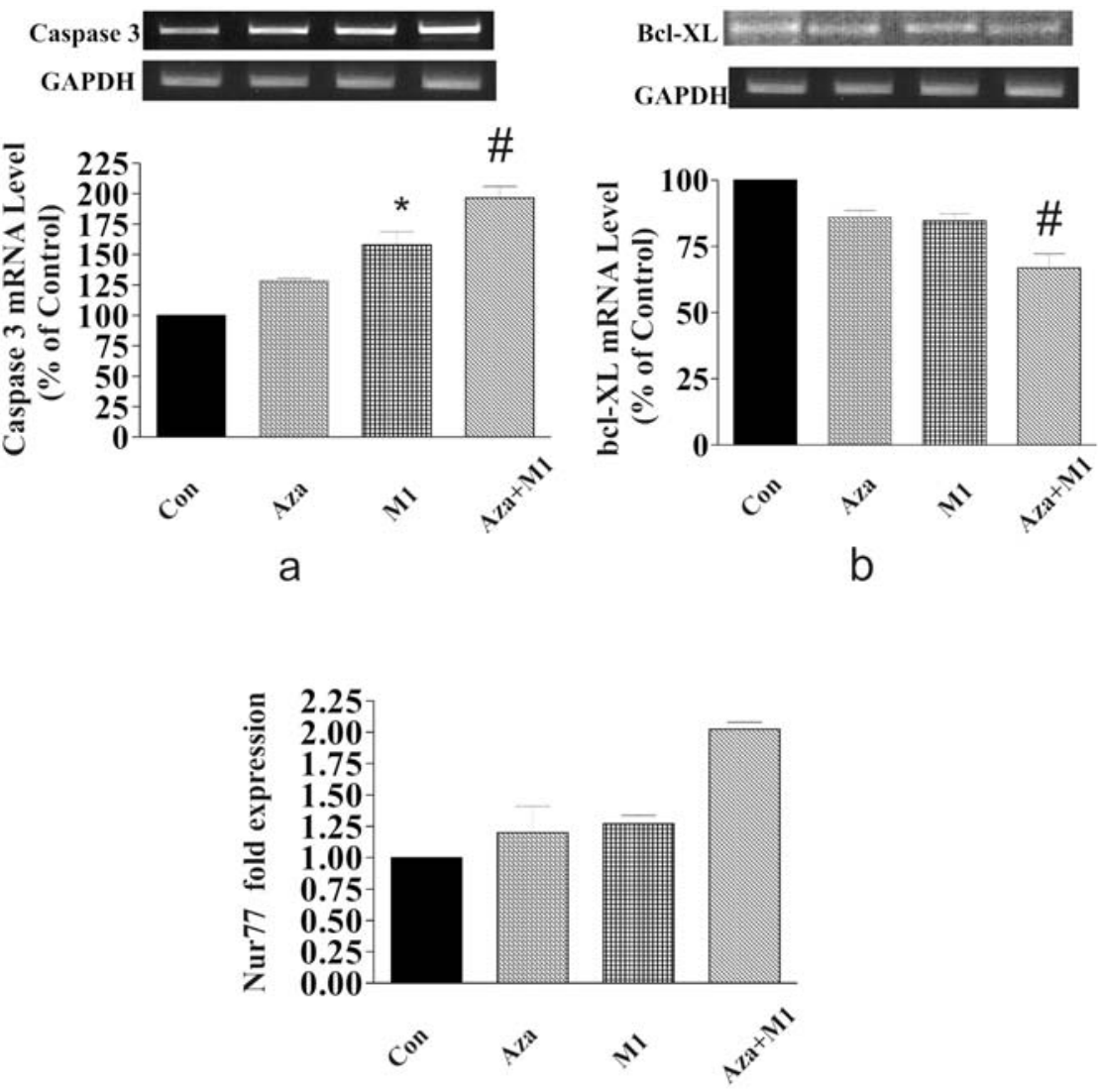

C

Figure 3. Effect of AZA and MCT-1 on Caspase-3, Bcl-XL and Nur77 mRNA expression in HL-60 cells. Con, HL-60 cells without treatment; AZA, cells treated with $1.0 \mu \mathrm{M}$ AZA; M1, cells treated with $0.5 \mu \mathrm{M}$ MCT-1; AZA+M1, cells treated with $0.5 \mu \mathrm{M}$ MCT-1 + $1.0 \mu \mathrm{M}$ AZA for $24 \mathrm{~h}$. ${ }^{*} \mathrm{P}<0.05 \mathrm{M} 1 \mathrm{vs}$. con; ${ }^{\#} \mathrm{P}<0.01$ $\mathrm{AZA}+\mathrm{M} 1$ vs. con and $\mathrm{n}=3$.
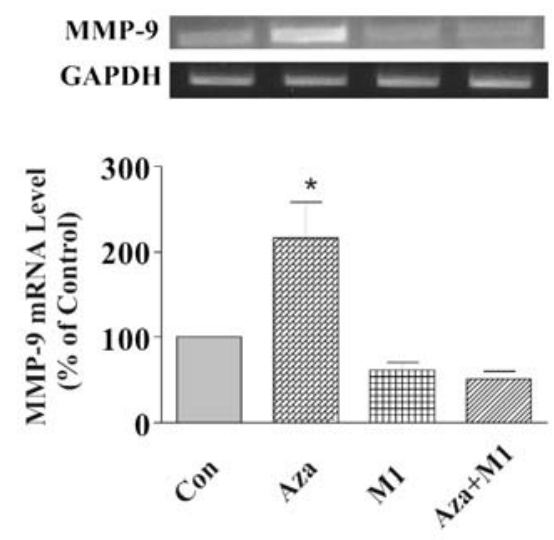

a

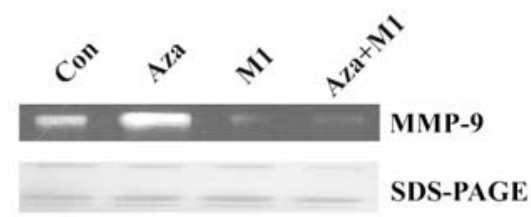

b

Figure 4. Effect of AZA and MCT-1 on MMP-9 mRNA expression and AZA-induced MMP-9 proteolytic activity in HL-60 cells. Con, HL-60 cells without treatment; AZA, cells treated with $1.0 \mu \mathrm{M}$ AZA; M1, cells treated with $0.5 \mu \mathrm{M}$ MCT-1; AZA+M1, cells treated with $0.5 \mu \mathrm{M}$ MCT-1 + $1.0 \mu \mathrm{M}$ AZA for $24 \mathrm{~h} .{ }^{*} \mathrm{P}<0.01 \mathrm{AZA}$ vs. con, M1 and AZA+M1 and $\mathrm{n}=3$. may have improve apoptotic and growth inhibitory activity over single agent treatment (Fig. 1). Whilst dosing order of HDACi and AZA may be of importance in determining the effects of these agents (13), recent studies suggest effects on cell viability are independent of the sequence of administration (8) and are reflected by our decision to treat cells concomitantly with MCT-1 and AZA in combination studies. In reviewing the histone acetylation pattern of the agents used in our studies we have identified augmentation of MCT-1mediated histone H3 acetylation by AZA (Fig. 1c). Previous studies utilizing the butyrate analogue valproic acid in combination with 5-aza-2'-deoxycytidine demonstrate enhanced histone $\mathrm{H} 3$ acetylation over single agent treatment (8). These effects have been postulated to result from demethylating agent-mediated opening of chromatin structure facilitating enhanced histone acetylation (8).

To assess the mechanism of action of the combination of AZA and MCT-1, we investigated the effects of these agents on several apoptosis and cell cycle associated genes in HL-60 cells. The effects of AZA on enhanced p15 $5^{\text {INK4b }}$ expression have been well documented, are considered a marker of gene demethylation and are thought pivotal in the therapeutic activity of this agent $(4,5,26)$. Results of our studies demonstrated $\mathrm{p} 15^{\mathrm{INK} 4 \mathrm{~b}}$ expression was, as expected, reactivated by AZA (Fig. 2). MCT-1 alone also increased p15 INK4b expression, one of only two other HDACi to have demonstrated this effect (15). Encouragingly, the combination of 
AZA and MCT-1 resulted in a significant increase in expression of $\mathrm{p} 15^{\mathrm{INK} 4 \mathrm{~b}}$ over single agent treatment.

Recent evidence suggests that epigenetic silencing of the cyclin-dependent kinase inhibitor $\mathrm{p} 21^{\mathrm{WAF} / \mathrm{CIP} 1}$ is also implicated in the pathogenesis of some hematological malignancies (9). We identified a minor increase in $\mathrm{p} 21^{\mathrm{WAF} 1 / \mathrm{CIP} 1}$ expression with AZA or MCT-1 alone, whilst addition of a combination of MCT-1 to AZA significantly increased expression of p $21^{\mathrm{WAF} 1 / \mathrm{CIP} 1}$ (Fig. 2). Significant induction of both $\mathrm{p} 15^{\mathrm{INK} 4 \mathrm{~b}}$ and $\mathrm{p} 21^{\mathrm{WAF} 1 / \mathrm{CIP} 1}$ by the combination of AZA and MCT-1 may in part provide a molecular mechanism for the enhanced apoptotic and cell inhibitory activity identified over single agent treatment in our study.

In addition to inhibition of cell cycle progression modulation of apoptotic pathway components affords a potential mechanistic explanation for the observed effects of the combination of AZA and MCT-1. Previous studies suggest demethylating agents and/or HDACi induce apoptosis reliant on activation of the effector Caspase-3 and down-regulation of the anti-apoptotic molecule Bcl-XL $(7-9,18)$. Our results concur with these observations and indicate that MCT-1 alone was more effective than AZA at inducing Caspase-3 expression and that the combination of AZA and MCT-1 was more effective than either compound alone at significantly attenuating Bcl-XL expression (Fig. 3). Together these observations provide additional evidence of the molecular mechanism responsible for the biological activity of the combination of AZA and MCT-1.

Recently Mullican and co-workers reported that abrogation of both Nur77 and nor-1 results in development of acute myeloid leukemia in mice and down-regulation of Nor-1 and Nur77 was a common feature in leukemic blasts from human AML patients, suggesting these molecules may be acting as tumour suppressors and thus re-expression and/or activation of nor-1 and Nur77 may be of therapeutic relevance in the treatment of AML (23). The orphan nuclear receptor Nur77 has been reported to translocate from the nucleus to the mitochondria, bind $\mathrm{Bcl}-2$, release cytochrome $\mathrm{c}$ and induce apoptosis $(31,32)$ potentially explaining why loss of this molecule may predispose to leukemogenesis. We demonstrate for the first time that both AZA and MCT-1 treatment result in an increase in expression of Nur77 and the combination of MCT-1 and AZA significantly increased expression of Nur77 (Fig. 4). These results identify a potential molecular mechanism for enhanced apoptotic and growth inhibitory activity of the combination of AZA and MCT-1.

Previous in vitro studies of AZA-mediated reactivation of MMP expression and enhancement of cancer cell invasion sound a potential side effect warning for use of demethylating agents and may restrict their application in a range of otherwise clinically relevant circumstances (10-12). Our results identify for the first time in vitro attenuation of AZA-induced MMP-9 expression and proteolytic activity by concomitant administration of the HDACi MCT-1. These observations suggest that the established biological effect of the combination of AZA and MCT-1 may also afford protection from potential adverse effects associated with AZA treatment.

In summary, we have demonstrated in vitro augmentation of inhibition of cell growth and increased apoptosis in HL-60 cells treated with a combination of AZA and the novel HDACi MCT-1. These effects may be in part due to increased expression of p15 ${ }^{\text {INK } 4 \mathrm{~b}}$, Caspase-3, p $21^{\mathrm{WAF} 1 / \mathrm{CIP} 1}$ and Nur77 combined with down-regulation of Bcl-XL. AZA-induced MMP-9 expression is completely attenuated by addition of MCT-1. Taken together these results suggest that the combination of AZA and MCT-1 has significantly more apoptotic and growth inhibitory activity than single agent treatment, utilizes molecular machinery involving multiple cell and apoptosis-associated molecules together with a putative tumour suppressor gene and may protect from adverse outcomes associated with use of demethylating agents alone.

\section{References}

1. Feinberg AP and Tycko B: The history of cancer epigenetics. Nat Rev Cancer 4: 143-153, 2004.

2. Toyota M, Kopecky KJ, Toyota MO, Jair KW, Willman CL and Issa JP: Methylation profiling in acute myeloid leukemia. Blood 97: 2823-2829, 2001.

3. Garcia-Manero G, Daniel J, Smith TL, Kornblau SM, Lee MS and Kantarjian HM: DNA methylation of multiple promoterassociated $\mathrm{CpG}$ islands in adult acute lymphocytic leukemia. Clin Cancer Res 8: 2217-2224, 2002.

4. Uchida T, Kinoshita T, Nagai H, Nakahara Y, Saito H and Hotta T: Hypermethylation of the p15INK4B gene in myelodysplastic syndromes. Blood 90: 1403-1409, 1997.

5. Daskalakis M, Nguyen TT, Nguyen C, Guldberg P, Kohler G and Wijermans P: Demethylation of a hypermethylated P15/INK4B gene in patients with myelodysplastic syndrome by 5-aza-2'-deoxycytidine [decitabine] treatment. Blood 100: 2957-2964, 2002.

6. Griffiths EA and Gore SD: DNA methyltransferase and histone deacetylase inhibitors in the treatment of myelodysplastic syndromes. Semin Hematol 45: 23-30, 2008.

7. Hackanson B, Robbel C, Wijermans $\mathrm{P}$ and Lubbert M: In vivo effects of decitabine in myelodysplasia and acute myeloid leukemia: review of cytogenetic and molecular studies. Ann Hematol 84: 32-38, 2005.

8. Yang H, Hoshino K, Sanchez-Gonzalez B, Kantarjian H and Garcia-Manero G: Antileukemia activity of the combination of 5-aza-2'-deoxycytidine with valproic acid. Leuk Res 29: 739-748, 2005.

9. Weber A, Hengge UR, Bardenheuer W, Tischoff I, Sommerer F, Markwarth A, Dietz A, Wittekind C and Tannapfel A: SOCS-3 is frequently methylated in head and neck squamous cell carcinoma and its precursor lesions and causes growth inhibition. Oncogene 24: 6699-6708, 2005.

10. Sato N, Maehara N, Su GH and Goggins M: Effects of 5-aza-2'deoxycytidine on matrix metalloproteinase expression and pancreatic cancer cell invasiveness. J Natl Cancer Inst 95: 327-330, 2003.

11. Chicoine E, Esteve PO, Robledo O, Van Themsche C, Potworowski EF and St-Pierre Y: Evidence for the role of promoter methylation in the regulation of MMP-9 gene expression. Biochem Biophys Res Commun 297: 765-772, 2002.

12. Couillard J, Demers M, Lavoie G and St-Pierre Y: The role of DNA hypomethylation in the control of stromelysin gene expression. Biochem Biophys Res Commun 342: 1233-1239, 2006.

13. Cameron EE, Bachman KE, Myohanen S, Herman JG and Baylin SB: Synergy of demethylation and histone deacetylase inhibition in the re-expression of genes silenced in cancer. Nat Genet 21: 103-107, 1999.

14. Marks PA and Breslow R: Dimethyl sulfoxide to vorinostat: development of this histone deacetylase inhibitor as an anticancer drug. Nat Biotechnol 25: 84-90, 2007.

15. Hitomi T, Matsuzaki Y, Yokota T, Takaoka Y and Sakai T: p15(INK4b) in HDAC inhibitor-induced growth arrest. FEBS Lett 554: 347-350, 2003.

16. Roh MS, Kim CW, Park BS, Kim GC, Jeong JH, Kwon HC, Suh DJ, et al: Mechanism of histone deacetylase inhibitor Trichostatin A induced apoptosis in human osteosarcoma cells. Apoptosis 9: 583-589, 2004. 
17. Sonnemann J, Hartwig M, Plath A, Saravana Kumar K, Muller C and Beck JF: Histone deacetylase inhibitors require caspase activity to induce apoptosis in lung and prostate carcinoma cells. Cancer Lett 232: 148-160, 2006.

18. Choi YH: Apoptosis of U937 human leukemic cells by sodium butyrate is associated with inhibition of telomerase activity. Int J Oncol 29: 1207-1213, 2006

19. Ailenberg M and Silverman M: Trichostatin A-histone deacetylase inhibitor with clinical therapeutic potential-is also a selective and potent inhibitor of gelatinase A expression. Biochem Biophys Res Commun 298: 110-115, 2002.

20. Liu LT, Chang HC, Chiang LC and Hung WC: Histone deacetylase inhibitor up-regulates RECK to inhibit MMP-2 activation and cancer cell invasion. Cancer Res 63: 3069-3072, 2003.

21. Hsu MC, Chang HC and Hung WC: HER-2/neu represses the metastasis suppressor RECK via ERK and Sp transcription factors to promote cell invasion. J Biol Chem 281: 4718-4725, 2006.

22. Jang TH and Sun SH: Alterations in $\mathrm{Ca}^{2+}$ signaling and c-fos and nur77 expression are associated with sodium butyrate-induced differentiation of C6 glioma cell. Chin J Physiol 43: 149-158, 2000

23. Mullican SE, Zhang S, Konopleva M, Ruvolo V, Andreeff M, Millbrant J and Conneely OM: Abrogation of nuclear receptors $\mathrm{Nr} 4 \mathrm{a} 3$ and Nr4a1 leads to development of acute myeloid leukemia. Nat Med 13: 730-735, 2007.

24. Lemaire M, Momparler LF, Farinha NJ, Bernstein M and Momparler RL: Enhancement of antineoplastic action of 5-aza2'-deoxycytidine by phenylbutyrate on L1210 leukemic cells. Leuk lymphoma 45: 147-154, 2004.

25. Shaker S, Bernstein M, Momparler LF and Momparler RL: Preclinical evaluation of antineoplastic activity of inhibitors of DNA methylation (5-aza-2'-deoxycytidine) and histone deacetylation (trichostatin A, depsipeptide) in combination against myeloid leukemic cells. Leuk Res 27: 437-444, 2003.
26. Gore SD, Baylin S, Sugar E, Carraway H, Miller CB, Carducci M, Grever M, et al: Combined DNA methyltransferase and histone deacetylase inhibition in the treatment of myeloid neoplasms. Cancer Res 66: 361-369, 2006.

27. Soriano AO, Yang H, Faderl S, Estrov Z, Giles F, Ravandi F, Cortes J, et al: Safety and clinical activity of the combination of 5-azacytidine, valproic acid, and all-trans retinoic acid in acute myeloid leukemia and myelodysplastic syndrome. Blood 110: 2302-2308, 2007

28. Sonoda H, Nishida K, Yoshioka T, Ohtani M and Sugita K: Oxamflatin: A novel compound which reverses malignant phenotype to normal one via induction of Jun D. Oncogene 13: 143-149, 1996.

29. Kim YB, Lee KH, Sugita K, Yoshida M and Horinouchi S: Oxamflatin is a novel anti-tumor compound that inhibits mammalian histone deacetylase. Oncogene 18: 2461-2470, 1999.

30. Dear AE, Mayes P, Liu HB and Perlmutter P: Novel conformational analogues of oxamflatin as histone deacetylase inhibitors. Organ Biomol Chem 21: 3778-3784, 2006.

31. Ekert PG and Vaux DL: The mitochondrial death squad: hardened killers or innocent bystanders? Curr Opin Cell Biol 17: 626-630, 2005.

32. Lin B, Kolluri SK, Lin F, Liu W, Han YH, Cao X, Dawson MI, et al: Conversion of $\mathrm{Bcl}-2$ from protector to killer by interaction with nuclear orphan receptor Nur77/TR3. Cell 116: 527-540, 2004. 